\title{
The Role of Agriculture in the Dissemination of Class 1 Integrons, Antimicrobial Resistance, and Diversity of Their Gene Cassettes in Southern China
}

\author{
Niyaz Ali ${ }^{1}$, Yinfu Lin ${ }^{1}$, Zhen Qing ${ }^{1}$, Dan Xiao ${ }^{1}$, Ahmad Ud Din ${ }^{2}{ }^{(}$, Izhar Ali ${ }^{1}(\mathbb{O}$, \\ Tengxiang Lian ${ }^{3}$, Baoshan Chen ${ }^{1,4}$ and Ronghui Wen ${ }^{1, * \mathbb{D}}$ \\ 1 State Key Laboratory for Conservation and Utilization of Subtropical Agro-Bio-Resources, College of Life \\ Science and Technology, Guangxi University, Nanning 530004, China; 1708401009@st.gxu.edu.cn (N.A.); \\ 1608403003@st.gxu.edu.cn (Y.L.); 1708401006@st.gxu.edu.cn (Z.Q.); 1808301057@st.gxu.edu.cn (D.X.); \\ Izharali48@gmail.com (I.A.); chenyaoj@gxu.edu.cn (B.C.) \\ 2 Drug Discovery Research Center, South West Medical University, Luzhou 646000, China; \\ ahmadnwa@swmu.edu.cn \\ 3 State Key Laboratory for Conservation and Utilization of Subtropical Agro-Bio-Resources, \\ South China Agricultural University, Guangzhou 510642, China; liantx@scau.edu.cn \\ 4 Guangxi Key Lab for Sugarcane Biology, College of Agriculture, Guangxi University, Nanning 530004, China \\ * Correspondence: wenrh@gxu.edu.cn; Tel.: +86-13669614062
}

Received: 19 July 2020; Accepted: 26 August 2020; Published: 28 August 2020

\begin{abstract}
Integrons are hot spots for acquiring gene cassettes from the environment and play a major role in the bacterial evolution and dissemination of antimicrobial resistance (AMR), thus posing a serious threat. There are currently studies on integrons and antibiotic resistance genes; however, the presence and association of integrons in different agricultural crops and their subsequent dissemination and role in AMR have not been reported previously. This study examines the abundance of integrons, their gene cassette diversity in various crop soils, and their role in the dissemination of AMR in the southern region of China. Samples from different agri-crop soil, such as rice (R.S), sugarcane (S.S), citrus (C.S), banana (B.S), agricultural runoff (the point where the runoff of all sites meet (R.O)), and wild (non-agricultural) soil (W.S), were collected. Quantitative PCR was used to determine the abundance of integrons, and clone libraries were constructed to examine the gene cassette arrays. All the tested samples were found positive for Class-I (CL1) integrons and revealed a higher concentration and higher relative abundance of R.S than the others, with the least found at the W.S site. The W.S CL1 cassette arrays were found empty, and no putative conserved domains were found. The R.O was found to contain a high number of gene cassettes with various functions, while the smallest number of gene cassettes was found in the S.S among the crop soils. Most of the gene cassettes presented by the R.O were primarily shared with other sites, and the antibiotic-resistant genes were consistently observed to be dominant. The constructed clone libraries represented a diverse gene cassette array with $16 \%$ novel gene cassettes that play a vital role in pathogenesis, transportation, biosynthesis, and AMR. Most resistance-related gene cassettes were associated with the genes encoding resistance to quaternary ammonium compound (QAC) and aminoglycosides. This study highlights the significant differences in the abundance of integrons among various agricultural soils and offers deep insight into the pools of gene cassettes that play a key role in the dissemination of integrons and AMR.
\end{abstract}

Keywords: integrons; gene cassettes; agriculture system; antimicrobial resistance 


\section{Introduction}

Bacterial genomes contain versatile gene accretion systems called integrons, which are commonly found in most gram-negative bacteria. Integrons are documented to be involved in the propagation and expression of genes in the bacterial community and play a major role in bacterial evolution, including antimicrobial resistance (AMR) development [1,2]. Integrons contain two common characteristics, a structural part and an array of gene cassettes (GCs). The 5' conserved region ( $\left.5^{\prime} \mathrm{C} . \mathrm{S}\right)$ consists of an integron integrase (intI) gene, an integron-associated recombination site (attI), and an integron-associated promoter (Pc) site. This platform captures and expresses GCs that are non-replicative mobile elements in the bacterial genome. These GCs consist of one or more open reading frame (ORF) and recombination cassette, joining the attC site. A site-specific tyrosine recombinase enzyme called integron integrase is encoded by the intI gene, which has a specific activity of integration and excision of GCs. The expression of integrase genes can be induced by the accumulation of single-stranded DNA in a bacterial cell via conjugation, transformation, starvation, and/or exposure to antibiotics [3,4]. Integrons play a key role in bacterial evolution through the adaptation of GCs and the expression of their different ORFs along with their subsequent role in developing adaptive antibiotic resistance [5,6]. Integrons are classified into three broad groups based on the phylogeny of their respective integrase genes. The first group is found in Proteobacteria from freshwater and soil environments, including the clinically important Class 1 and Class 3 integrons [7,8]. The second group is found in gamma Proteobacteria from marine environments and consists of Class 2 integrons and integrons found on the plasmids of Vibrio [7-9]. The third group of integrons features those whose integrase genes are oriented in the reverse direction of the first and second groups of integron integrase genes and are found in the members of Spirochetes, Plantomycetes, Cynaobacteria, and Chlorobi spp., which are native to various environments $[7,10]$. Among them, Class 1 integrons have been found to play a key role in the development of antibiotic resistance [11,12]. Hundreds of GCs carried by integrons have demonstrated their role in resistance to different classes of antibiotics, such as amino glycosides, beta-lactams, chloramphenicol, trimethoprim, and streptothricin [12,13].

Moreover, gene cassettes are widely dispersed in diverse environments, and different GCs are often expressed by the same bacterial species $[14,15]$. The functions of the predicted proteins of the ORFs within GCs are wide-ranging. In addition to antibiotic resistance, they are involved in virulence and secondary metabolism, which are more specific to these species [3,11]. Most studies on integrons and their metagenomic analyses demonstrated that most GCs are novel $[16,17]$. To investigate GCs in different environments, the PCR-based amplification of GCs is commonly used following a metagenomic analysis using genomic DNA as a template [18,19]. Furthermore, many studies proved the dispersion of integrons in a wide range of environments, such as sediments, rivers, oceans, soils, plant surfaces, the rhizosphere, bio-films, hot springs, and Antarctic soils [9]. Furthermore, the presence of antibiotics in agriculture water [20] may affect the soil microbial community [21], as well as instigate antimicrobial resistance in soil microbes [22]. On the other hand, the presence of various soil contaminants, soil compositions, and microbial biomasses may influence the soil microbiome and enhance the dissemination of antibiotic resistance genes (ARGs) $[23,24]$.

Manure is commonly used as an organic fertilizer to upgrade the fertility of agricultural soils. The induction of manure to the soil introduces vast bacterial communities that carry antibiotic resistance genes (ARGs) present on mobile genetic elements (MGEs) [25,26]. These ARGs are transferred into the soil's bacterial communities through a process called horizontal gene transfer [27]. The application of manure may result in the enrichment of bacterial taxa, including human pathogens [28]. On the other hand, the soil's natural reservoirs present their own sets of known and unknown ARGs [29]. Due to the selective pressure imposed by the application of antibiotic agents (ABAs) to the soil, the resilience of soil bacteria against manure application is decreased in the presence of ABA [28]. The wastewater, treated water, and lake water all contain ARGs [30]. Thus, the water used for irrigation purposes from these sites poses a risk of transmitting antibiotic resistance ABR and ARGs [31]. Organic and inorganic 
fertilization impacts the abundance of $A B R$ and integrons in the soil environment by introducing resistant bacteria $[32,33]$.

The dissemination of integrons is very common in most of the environment, and anthropogenic inputs play a vital role in this phenomenon [34]. The agricultural system covers a vast environment and requires a deep insight to investigate the representation of CL1 integrons and their GCs, which reside in these crops' environments. Thus far, there have been no studies on various agri-crops and their impacts on both integrons and the gene cassette pools at these sites, especially on the crop soil environment and the effluent discharge from these environments. The current study investigates integron dissemination and GCs in different crop systems and establishes their contributions to the rise of antimicrobial resistance.

\section{Materials and Methods}

\subsection{Samples Collection}

Soil samples were collected from a typical farming area (between longitude $107^{\circ} 58^{\prime}-107^{\circ} 90^{\prime}$ and latitude $22^{\circ} 47^{\prime}-22^{\circ} 55^{\prime}$ ) located at Fusui county, which is a typical karst region in southern China whose main crops include sugarcane, rice, bananas, and citrus. Soil samples were collected from each of these agriculture fields, considering each crop field as a separate site for sample collection. The soils of different fields, including rice soil (R.S), citrus fields (C.S), sugarcane fields (S.S), banana fields (B.S), wild soil (non-agricultural sites where the anthropogenic input is very limited, W.S), and agricultural runoff (the point where the runoff of all sites meet, R.O), were collected. The collected samples were then preserved at $-80^{\circ} \mathrm{C}$ for further use. The soil properties including $\mathrm{pH}$, organic matter $(\mathrm{OM})$, available phosphorous (AP), available potassium (AK), total potassium (TK), total phosphorous (TP), total nitrogen (TN), available nitrogen (AN), total carbon (TC) and C:N ratio were measured as previously described by Ali et. al. [35] and the values are presented in Table 1.

Table 1. Properties of the different sites.

\begin{tabular}{ccccccc}
\hline Properties & W.S & R.O & R.S & C.S & B.S & S.S \\
\hline $\mathrm{pH}($ water $)$ & 7.33 & 8.62 & 6.81 & 4.44 & 6.74 & 5.04 \\
$\mathrm{OM}(\mathrm{g} / \mathrm{kg})$ & 13.57 & 17.53 & 47.16 & 36.18 & 53.57 & 15.89 \\
$\mathrm{AP}(\mathrm{mg} / \mathrm{kg})$ & 5.23 & 60.37 & 31.00 & 278.3 & 66.33 & 8.02 \\
$\mathrm{AK}(\mathrm{mg} / \mathrm{kg})$ & 22.07 & 68.17 & 132.76 & 278.6 & 347.39 & 39.53 \\
$\mathrm{TK}(\mathrm{g} / \mathrm{kg})$ & 2.14 & 1.97 & 1.59 & 1.99 & 3.67 & 2.65 \\
$\mathrm{TP}(\mathrm{g} / \mathrm{kg})$ & 0.78 & 0.74 & 0.92 & 1.19 & 2.50 & 0.64 \\
$\mathrm{TN}(\mathrm{g} / \mathrm{kg})$ & 1.16 & 0.68 & 2.13 & 1.22 & 2.49 & 0.69 \\
$\mathrm{AN}(\mathrm{mg} / \mathrm{kg})$ & 56.82 & 47.69 & 172.88 & 108.6 & 102.2 & 60.07 \\
$\mathrm{Total} \mathrm{C}$ & 7.87 & 10.17 & 27.36 & 21.0 & 31.07 & 9.22 \\
$(\mathrm{~g} / \mathrm{kg})$ & & & & 17.27 & 12.47 & 13.31 \\
$\mathrm{C}: \mathrm{N} \mathrm{ratio}$ & 6.81 & 15.02 & 12.87 & 17.27
\end{tabular}

Note: OM—organic matter, AP-available phosphorous, AK-available potassium, TK-total potassium, TP—total phosphorous, TN—total nitrogen, $\mathrm{AN}$ - available nitrogen, $\mathrm{TC}$ - total carbon and C:N ratio - carbon to nitrogen ratio, W.S — wild site, R.O-agricultural runoff site, R.S—rice field site, C.S—citrus field site, B.S—banana site, S.S- sugarcane site.

\subsection{DNA Extraction}

DNA was extracted using the soil DNA extraction kit according to the manufacturer's instruction (QIAGEN, Korea Ltd., Seoul, Korea), and the concentration of DNA in each sample was quantified using Nano drop (model one C). The extracted DNA samples were preserved at $-80^{\circ} \mathrm{C}$ for the follow-up experiments. 


\subsection{CLASS 1 Integrons Detection and 16 SrRNA}

To amplify the Class 1 integron, forward (5'-ATCATCGTCGTAGAGACGTCGG-3') and reverse primers ( $5^{\prime}$-GTCAAGGTTCTGGACCAGTTGC- $\left.3^{\prime}\right)$ were used as described previously by Rosser et al. [36]. The primer pair for 16SrRNA (forward 5'-CGGTGAATACGTTCYCGG-3' and reverse primer 5'-GGTACCTTGTTACGACTT-3) was used as described by Gaze et al. [37]. The PCR reactions were conducted in a reaction volume of $50 \mu \mathrm{L}$, and the amplified fragments were separated using gel electrophoresis for visualization. The different bands were cut from the gel and extracted using a gel extraction kit (Vazyme, Nanjing, China) according to the manufacturer's instructions. The DNA fragments were cloned into a blunt cloning vector using a TA/Blunt-Zero Cloning Kit (Vazyme, Nanjing, China), according to the manufacturer's instructions, and accordingly transferred into E. coli $\mathrm{DH}_{5 \alpha}$ competent cells. These cells were then cultured overnight on LA medium containing ampicillin at a concentration of $100 \mu \mathrm{g} / \mathrm{mL}$. The positive colonies were selected after overnight incubation, and the plasmids were extracted from the culture using a plasmid extraction kit (Vazyme, Nanjing, China). These recombinant plasmids were Sanger sequenced via a universal sequencing primer at AuGct Biotechnology Co. Ltd. (Beijing, China).

\subsection{The Gene Cassette Libraries}

To amplify the variable regions of Class 1 integrons, primer pairs were used [38] in a reaction mixture of $50 \mu \mathrm{L}$ containing $20 \mathrm{ng}$ of DNA, $25 \mu \mathrm{L} 2 \times$ premix Takara Ex Tag (Takara, Kusatsu, Japan), and $2.5 \mu \mathrm{L}$ of both primers. The PCR conditions were optimized as described previously [38,39]. Triplicates were amplified from each DNA sample, and the amplicons were pooled and purified with a Vazyme gel purification kit (Vazyme, Nanjing, China). The PCR purified products were then quantified and ligated into the M13 vector and transferred into the competent cells of E. coli $\mathrm{DH}_{5 \alpha}$ following the manufacturer's instructions (Vazyme, Nanjing, China). From each sample, 80 clones were selected randomly and sequenced after validation using a gene cassette size of $153 \mathrm{bp}$ via M13 reverse and forward primers. To avoid ambiguous bases, the sequences were confirmed after assembling the primer sequences, and the GCs were further analyzed when the sequences contained the two primer pairs ( $3^{\prime}$ C.S and $5^{\prime}$ C.S). The sequences were further annotated for nucleotide blast with BLASTN and BLASTX for protein [40]. The sequences that were annotated as hypothetical or had no hits in NCBI were further authenticated using the NCBI ORF finder (https://www.ncbi.nlm.nih.gov/orffifinder/).

\subsection{Quantitative PCR ( $q-P C R)$}

To quantify the abundance of Class 1 integron integrase genes and 16s rRNA genes, qPCR was conducted for all these samples, as reported by Barrud et al. [41]. SYBR ${ }^{\circledR}$ Premix Ex Taq ${ }^{\mathrm{TM}}$ II (Takara, Kusatsu, Japan) was used to conduct the qPCR using a Roche real-time PCR system. The conditions of amplifications were set as previously described [38,42], and the sample amplifications were carried out in triplicate. The standard curve was formed using serial dilution of the plasmids carrying the relevant gene fragments. The relative abundance of integron integrase genes was calculated by dividing the $16 \mathrm{~s}$ rRNA gene copy number by the copy number of the integrase gene.

\subsection{Statistical Analysis}

Statistix 8.1 (Analytical Software, 2105 Miller Landing Rd, Tallahassee, FL, USA) was used for the data analysis, and the figures were plotted using the Sigma Plot 12.5 (Systat Software, Inc. 1735 Technology Drive, Ste 430, San Jose, CA, USA) software and Origin 9.1 (OriginLab Corporatio, One Roundhouse Plaza, Suite 303, Northampton, MA, USA). The means of the replicates were compared using a least significant difference test with a 0.05 probability level. The shared GCs between all samples were picked, and the sharing network was visualized using Gephi (V0.8.1) [43]. All the sequences were submitted to NCBI with accession numbers from MT499916 to MT500005. 


\section{Results}

\subsection{Presence of Integrons and Abundance of CL1 Integron and 16srRNA}

Class (CL) 1 integron integrase genes were detected in all samples, and the 16s rRNA gene was amplified in all the collected samples. The CL2 and CL3 integrons were rarely detected in the agricultural effluent (R.O) and rice field samples (R.S), while the wild soil (non-agricultural soil) (W.S), sugarcane (S.S), banana (B.S), and citrus (C.S) soils were found to be negative for CL2 and CL3 integrons. CL2 and CL3 integrons are usually found in clinical settings and sometimes at wastewater treatment plants, which mostly contain human microbiota.

To determine the abundance/concentrations of integrons and 16s rRNA genes, qPCR was performed. The results showed that the abundance of CL1 integrons among all the samples was the highest in R.S, followed by R.O, while the fewest copies were observed in W.S (Figure 1). The 16s rRNA copy number was higher in the rice fields compared to the other samples, and the smallest number was found in the W.S $(p<0.05)$, which suggests that the high copy number of integrons in the other samples was due to the anthropogenic input. The other factors involved in the increased copy numbers in R.S include the introduction of manure and other fertilizers into the bulk amount of the fields, which were almost negative in the wild soil.

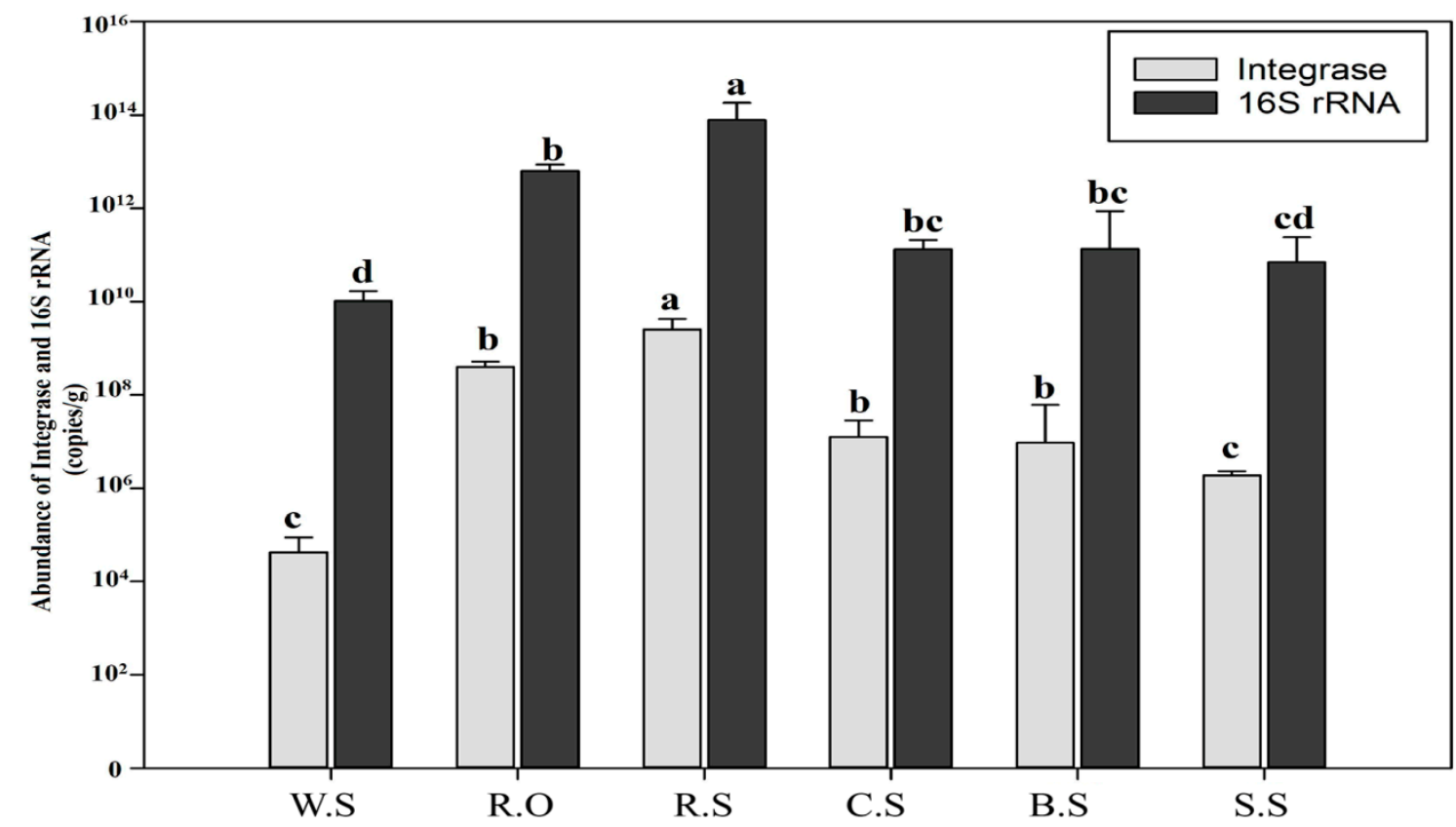

Figure 1. Concentration/copy number of the CL1 integron integrase gene and the 16S rRNA gene in each sample. The off-white bar indicates the concentration/copy number per gram of soil of the integrase gene in each soil sample, while the black bar indicates the 16Sr RNA copy number per gram of soil in each sample. Differences in the copy numbers of each sample group were evaluated using the Least Significant Difference (LSD). Different letters (a, b, c, d) above the column indicate statistical significance at $p$ values $<0.05$. W.S-wild site, R.O-agricultural runoff site, R.S-rice field site, C.S - citrus field site, B.S—banana site, S.S—sugarcane site. The wild soil sample contained the lowest concentration/fewest copy numbers of both integrase and 16S rRNA, while the highest copy numbers of both genes were found in the R.S samples followed by R.O, C.S, B.S, and S.S.

\subsection{Class 1 Integron Gene Cassette Pool}

To further analyze the integrons and their GCs, a library of nearly 500 clones was built. About $60 \%$ of the GCs were found to be empty, carrying no putative sequences. In the wild soil samples, more than 100 clones were generated. None of the clones showed any putative proteins, which clearly indicates that the integrons were mostly active during periods of anthropogenic or environmental 
stress and that bacteria exchanged the GCs under stress conditions. Overall, about $12 \%$ of the GCs were annotated as novel and showed no hits in a NCBI Blast. The most diverse GCs were found in the effluent soil, and about 42 different GCs were identified while assembling the sequences, resulting in about 22 different proteins being transcribed. The fewest variant GCs were found in the sugarcane soil, which shared about six types of dissimilar GCs. The most abundant GCs were quaternary ammonium compound (QAC) resistance genes, which were prevalent in all samples. Figure 2 highlights the different GCs in these environments

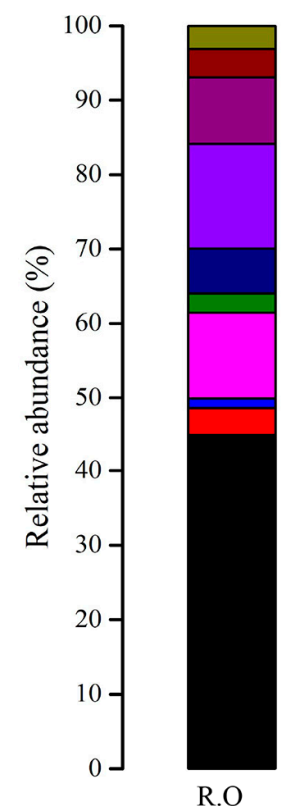

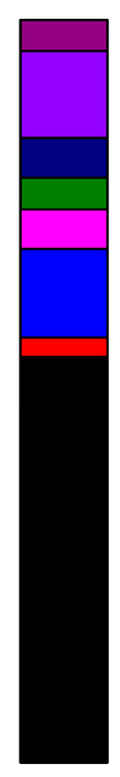

R.S

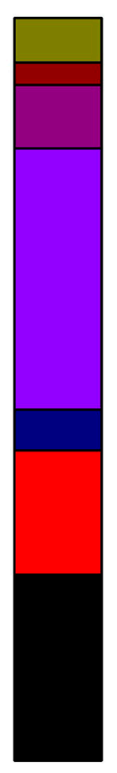

C.S

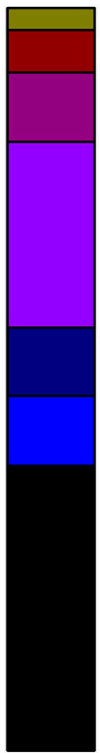

B.S

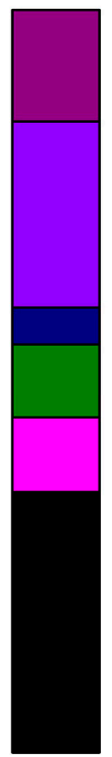

S.S $\square$ Membrane protein

Transpotrt protein

Biosynthesis protein

$\square$ Hypothetical protein

DNA,rep,Trans, Repair

$\square$ NO HITS

$\square \mathrm{ORF}$

DUF protein

$\square$ Transferases

Anitbiotic Resistant

Figure 2. The relative abundance of different GCs transcribed into various proteins with various functions are represented by different colors from the bottom to the top of the bars. The distances covered by the various colors represent the relative abundance in that specific site. R.O-agriculture runoff site, R.S-rice field site, C.S—citrus field site, B.S-banana site, S.S-sugarcane site. A bar with more colors shows that the site is more diverse. In this figure, the R.O site is more diverse, while the S.S site has the fewest variants.

\subsection{Shared Gene Cassette Network}

A shared gene network was also drawn to represent the GCs shared among these environments. A total of eight GCs were shared by these sites. Most of the GCs were shared by the R.O and C.S sites. Among the shared GCs, the most common were the ones harboring various types of aminoglycoside resistant genes. The same method was followed for the rest of the GCs. The most relevant GCs were merged and are represented in Figure 3. The other gene cassette shared by all sites involves a hypothetical protein. The results show that these GCs flow from different sites and accumulate at the R.O site. 


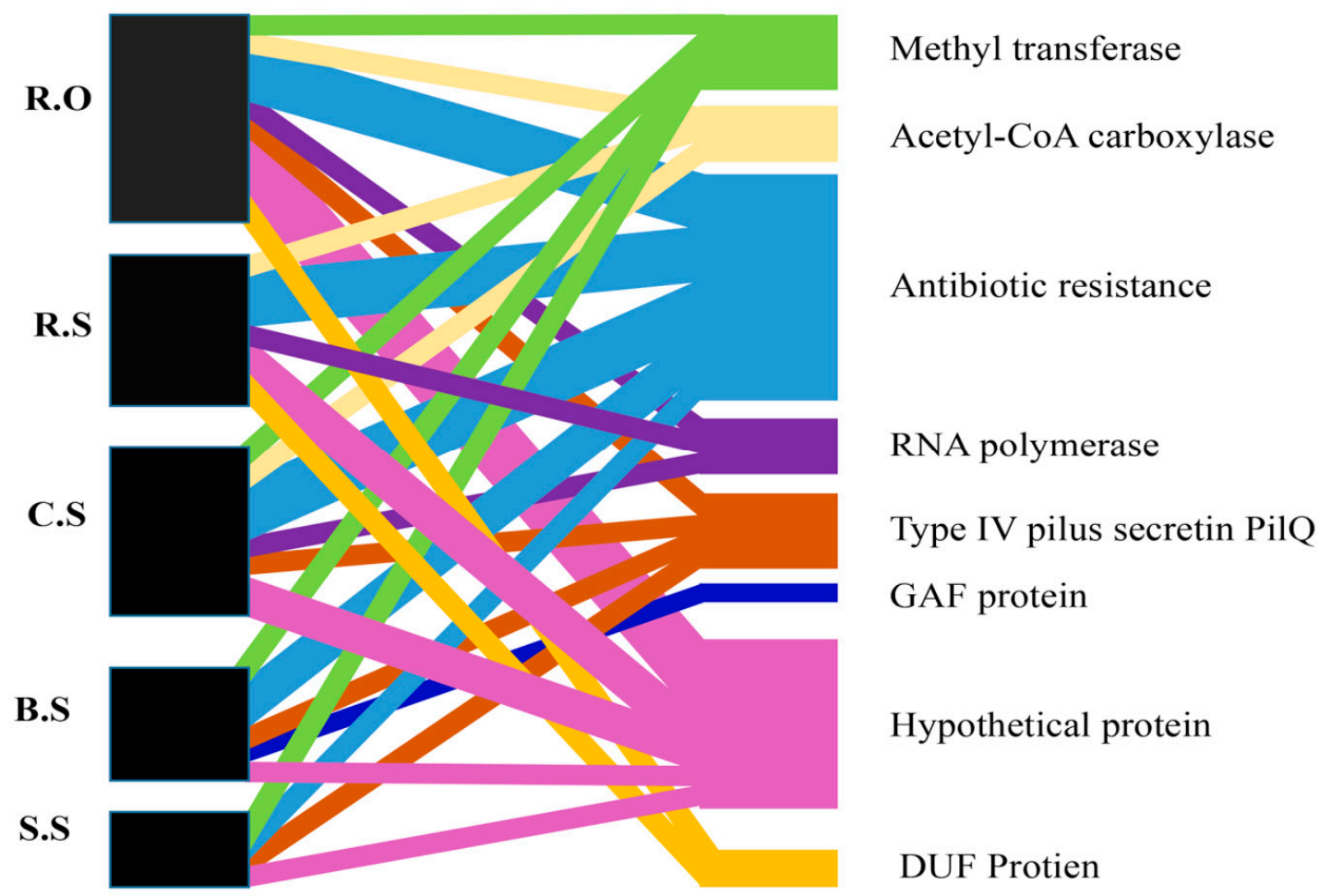

Figure 3. The shared gene cassette networks among the sites. The black box on the left side shows the sites, and the box's horizontal width shows the different proteins in that site. The various colors on the right side of the figure represent the different gene cassette proteins. The crossed lines of various colors between the two blocks show the presence of a specific protein, and the width of the line shows that protein's concentration in that specific site. R.O-agriculture runoff site, R.S-rice field site, C.S-citrus field site, S.S—sugarcane field site, B.S-banana field site. The line represents the association between various sites, while the different colors represent the various GCs.

\subsection{Unknown Gene Cassette Pool}

We also found some GCs related to stress, mobility, cell synthesis, chemotaxis, transport, and DNA repair. Interestingly, we found $1 \mathrm{~kb}$ GCs, which represent a particular type IV secretary conjugative DNA system that mediates interbacterial conjugative DNA transfer and the transfer of its DNA into eukaryotic cells such as Agrobacteruim tumeficians. Another $1.2 \mathrm{~kb}$ gene cassette was identified to carry the proteins of an ATP-binding cassette (ABC) transport system, which is an important part of the periplasmic transport system. Another gene cassette that transcribes the glycosyl hydrolase family 20 (GH20) catalytic domains of N-acetyl-beta-D-glucosaminidase enzymes, which is novel among the GCs of integrons. Moreover, this family features several functional forms of cell synthesis in pathogenesis. Figure 4 represents the observed and rarefied sequences. The analysis shows that the extensive sequencing of the GCs still did not identify all GCs in the sites. The Shannon index analysis shows that the diversity among the replicates is variable, which demonstrates that there are more diverse gene cassette pools among the various sites (Figure 5). 


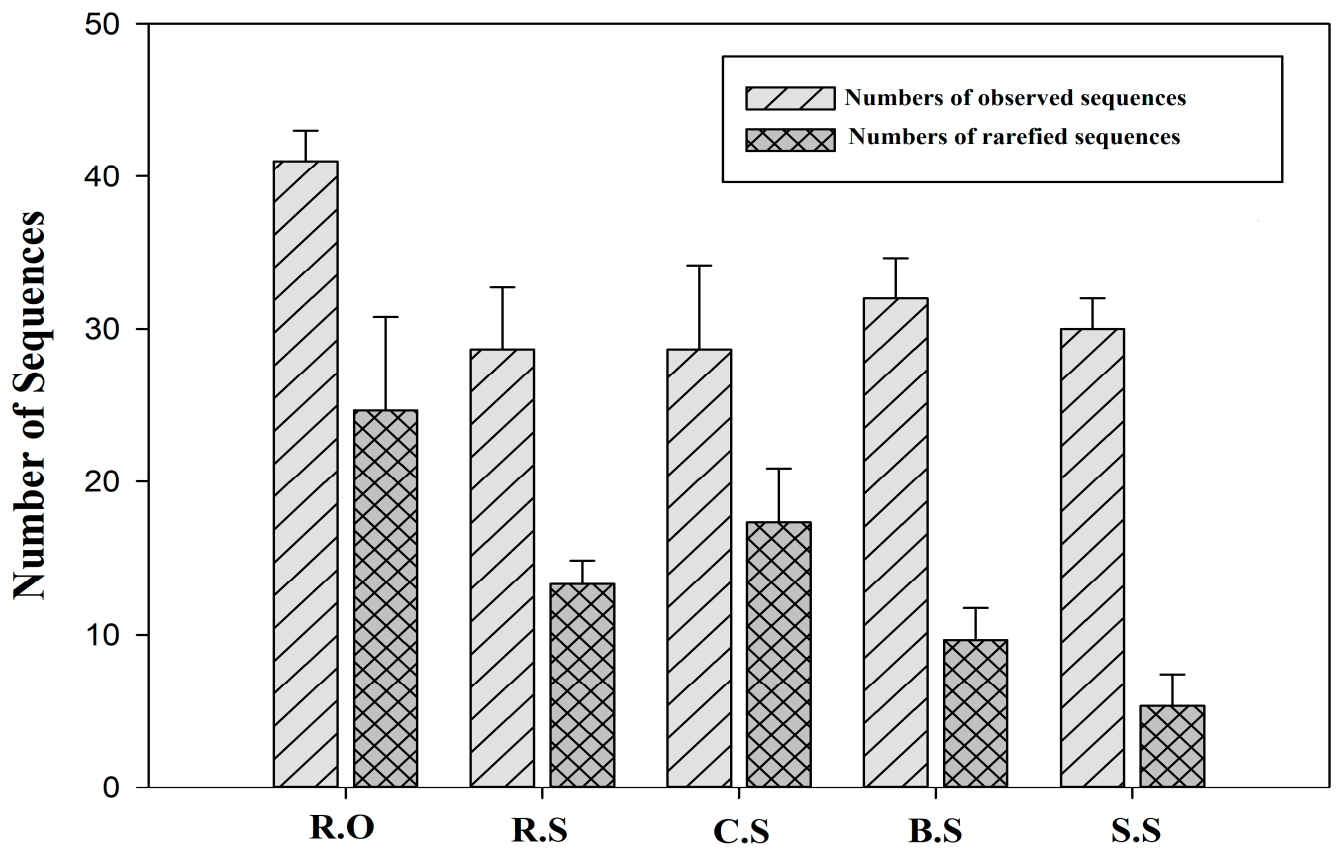

Figure 4. Number of observed and rarefied sequences (gene cassettes in each sample. R.O-agriculture effluent site, R.S—rice field site, C.S — citrus field site, B.S—banana site, S.S-sugarcane site. Each bar on the left indicates the average observed sequences, while the bars on the right indicate the rarefied sequences based on the clone libraries. Most rarefied sequences were higher for the R.O site, while the lowest numbers were found for the S.S site.
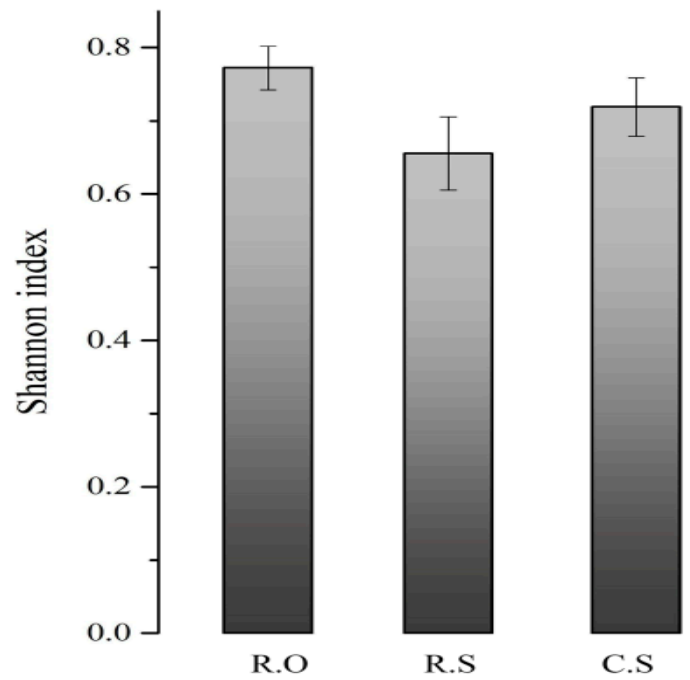

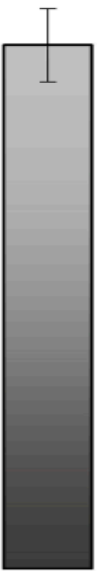

B.S

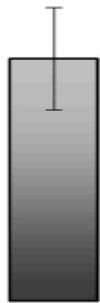

S.S

Figure 5. Diversity of GCs in Class 1 integrons in each sample. R.O-agriculture effluent site, R.S—rice field site, C.S — citrus field site, B.S—banana site, S.S—sugarcane site. The bars from left to right show the samples sites. From left to right, the most diverse site in terms of GCs was R.O, and the least diverse was S.S.

Another gene cassette was found, which harbored the co-enzyme F430, which catalyzed the reduction of methyl co-enzyme $\mathrm{M}$ to methane. Mostly anaerobic bacteria contain this enzyme, but there were no homologies in the database, which indicates the novelty of these sequences found in the integron gene cassette array (Figure 6B). Other GCs that harbor an enzyme called topoisomerase-primase are involved in the DNA repair system. We also found some transcription regulator GCs that play a role in transcription. 

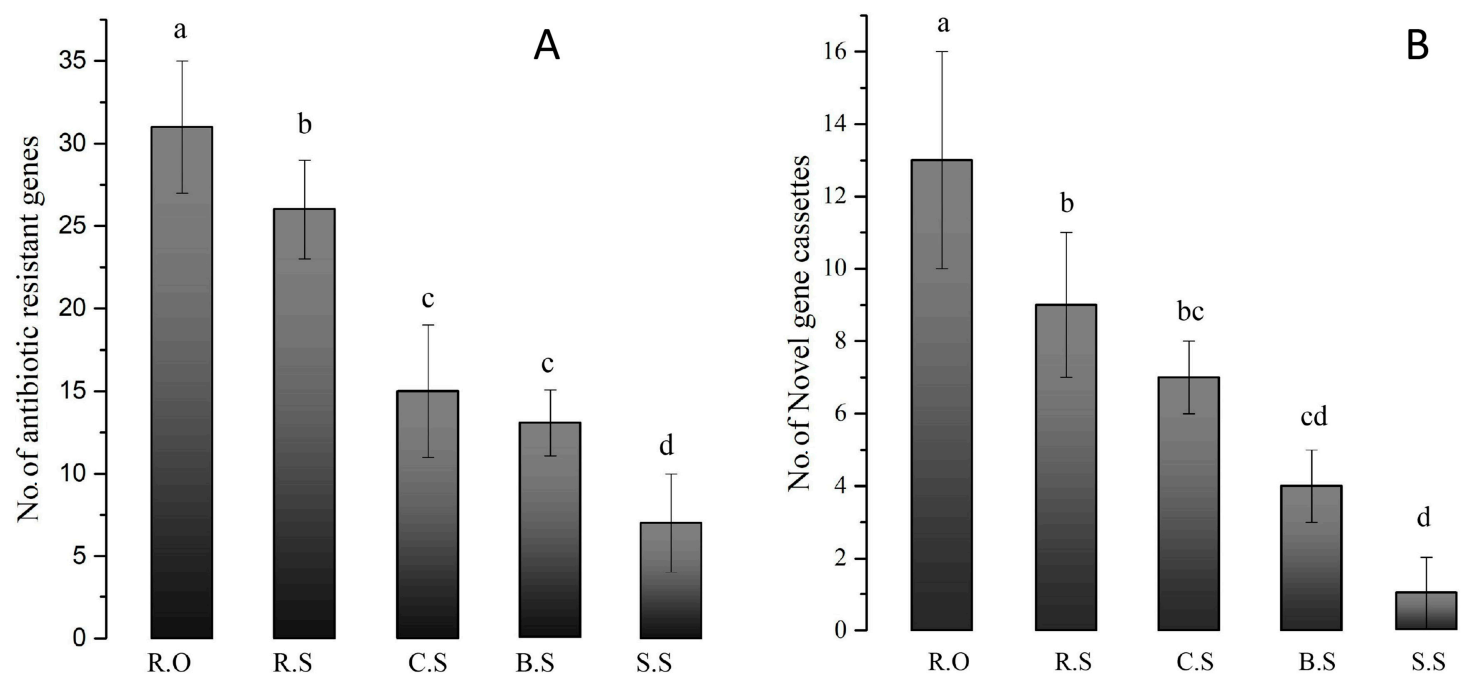

Figure 6. Numbers of antibiotic resistance genes (A) and novel GCs (B) observed in each sample. R.O—agriculture effluent site, R.S—rice field site, C.S—citrus field site, B.S—banana site, S.S—sugarcane sites. Different letters indicate different significant differences, while the error bars show the standard errors. Different letters (a, b, c, d) above the column indicate statistical significance at $p$ values $<0.05$. The highest number of antibiotic resistance GCs and novel GCs was found for the R.O site, and the lowest numbers were found for the S.S site.

\subsection{Various Antibiotic Resistance GCS}

Different antibiotic resistance GCs found in this study conferred resistance to amino glycosides, streptomycin, and penicillin. Resistant genes such as aadA1 aadA2, aacA3, dfrA, and QacG were frequently found in the agriculture effluent $(p<0.054)$, rice field, and soil samples. In contrast, aminogylcoside was found frequently in all samples (Figure 6A), except for the wild soil samples. Moreover, all cassettes from the wild soil samples were empty. Antibiotic resistance genes were frequently found in each sample, as described in Table 2.

Table 2. Clone numbers of the antibiotic resistance GCs detected in all samples.

\begin{tabular}{|c|c|c|c|c|c|c|}
\hline Gene family & Antibiotic Resistance Associated Gene & R.O & R.S & C.S & B.S & S.S \\
\hline Aminoglycoside & aadA1 gene & 3 & 3 & 4 & 1 & 1 \\
\hline Aminoglycoside & $\operatorname{aad} A 2$ & 1 & 1 & 0 & 0 & 2 \\
\hline Aminoglycoside & glycoside hydrolase & 1 & 0 & 1 & 0 & 1 \\
\hline Aminoglycoside & $(\operatorname{aac} A 3)$ & 1 & 0 & 0 & 0 & 0 \\
\hline $\begin{array}{l}\text { Quaternary } \\
\text { ammonium } \\
\text { resistance } \\
\text { protein }\end{array}$ & QacG & 3 & 1 & 6 & 1 & 0 \\
\hline Dehydrofolate & $D f r A$ & 2 & 0 & 0 & 0 & 0 \\
\hline Streptomycin & Streptomycin 3'-O-adenylyltransferase & 2 & 2 & 4 & 1 & 1 \\
\hline
\end{tabular}

Note: The first column shows the family of the gene, and the second row presents the associated gene, while the digit represents the number of GCs from that site. R.O-agriculture effluent site, R.S—rice field site, C.S - citrus field site, B.S-banana site, S.S - sugarcane site. The R.O sites present a diverse group of antibiotic resistance genes, while the fewest and least diverse antibiotic resistance genes are present in the S.S site.

\section{Discussion}

In this study, Class CL1 integrons were detected in soil samples from different agricultural systems, and the relative concentrations of 16Sr RNA were found to be highest in the rice field soil samples (R.S). In contrast, the lowest concentrations were found in the wild soil (W.S) samples. The incidence of CL1 integrons in the sugarcane field soil (S.S), banana field soil (B.S), and citrus field soil samples (C.S) was found to be lower than that in the agriculture effluent soil (R.O) and R.S. The net 
concentration of CL1 integrons was slightly lower than that previously reported in poultry waste or wastewater treatment plants but higher than that in freshwater sediments $[38,39,44,45]$. On the other hand, CL2 and CL3 integrons were barely detected (only found in R.S), whereas the agricultural runoff (R.O) and the other samples were found to be negative for these integrons. CL1 integrons were the most prevalent in the environment and are considered the dominant source for acquiring and spreading GCs [11,39]. Reports are limited on the detection of CL2 and CL3 integrons in soil environments $[46,47]$, though their presence was observed in E. coli isolates of animal and human fecal samples $[39,46,47]$. Their occurrence was also observed in low concentrations in wastewater environments [38]. CL2 and CL3 have limited functions compared to CL1 integrons, and their evolutionary history explains this lower abundance [12]. The integrase associated with CL2 and CL3 integrons often exists in an inactivated form and the integrons then become unable to acquire the external GCs from the environment into their arrays [11,12,39]. Water is considered the main source of agricultural contamination as it carries CL1 integrons and GCs and is considered the most obvious reason for the dissemination of integrons in the agricultural environment. The amendment of struvite, poultry waste, and manure and sludge increased the abundance of CL1 integrons and the gene cassette arrays in the bacterial communities in the soil [48-50]. Organic and inorganic fertilizers are considered to be sources of integrons and might have affected the concentration of CL1 integrons in our study. The increased incidence of CL1 in the rice field might be associated with the comparatively higher use of fertilizers in that soil [32]. Recently, struvite and biochar applied to the field have been reported to play a role in the abundance of CL1 integrons and GCs, particularly in a rhizosphere environment [39].

GCs are a substantial element of genomic diversity and play an important role in the genomic diversity of bacterial evolution [11,39]. The gene cassette analysis of our study revealed that many GCs have no homology in the database or with any other conserved hypothetical proteins. These findings are consistent with those of other studies related to environmental investigations of integron GCs and their subsequent integration and transfer to microbial communities [17,32]. Interestingly, we found a $1 \mathrm{~kb}$ gene cassette, which is a particular type IV secretary conjugative DNA system that mediates interbacterial conjugative DNA transfer and trans kingdom protein transfer into eukaryotic host cells in the process of pathogenesis. The sole bacterium that carries this type of gene is Agrobacteruim tumefaciens [51,52]. This gene also facilitates the adaptation of the organism to environmental stress and plays a basic role in the spread of antibiotic resistance among communities [53]. This observation further demonstrates that integron GCs play a vital role in the genetic evolution of bacteria through the acquisition of genes from other species $[53,54]$. Such areas are thus hotspots of antibiotic resistance evolution in bacteria and the reason for the horizontal gene transfer among them [32,39]. In this study, all the agricultural environments contained CL1 integrons and carried different types of antibiotic-resistant GCs. In contrast, the frequency of antibiotic resistance GCs was higher in the R.O sediments followed by R.S, C.S, S.S, and B.S. However, this frequency was still lower than that in hospital waste and wastewater treatment plants [38,45,55].

We found two novel GCs with sizes of $1.2 \mathrm{~kb}$ and $1 \mathrm{~kb}$; the former belongs to the ABC transport system (specifically to the ModA system of the periplasm), while the latter is a twin arginine-targeting protein translocase TatC protein. TatC is a component of the twin-argentine transport system and is highly conserved. Arginine transport is required to transport the folded proteins across the inner membrane [53]. At the same time, defects in this component lead to defects in colonization [56]. Beta-N-acetyl hexosaminidases of glycosyl hydrolase family 20 (GH20) GCs were also found in the present study. This family is commonly found in microorganisms, animals, and plants that are involved in physiological and pathological processes such as cell structure, energy, defense, inflammatory signaling, and lysosomal storage [57]. We also found another gene cassette that was transcribed into the co-enzyme F430 synthase, which is a prosthetic group of methyl co-enzyme M reductase that catalyzes the reduction of methyl co-enzyme $\mathrm{M}$ to methane [58]. We also observed other novel GCs related to DNA synthesis and transcription regulators that translate the enzyme's topoisomerase-primase and ring finger enzyme. Previous studies showed that these regulators have a high number of 
GCs related to biosynthesis and represent some GCs with the functions of chemotaxis, DNA repair, and regulation $[38,39,45]$.

Most of all GCs were found to be associated with resistance to amino glycosides and streptomycin. These findings are consistent with the previous observations of environmental GCs from wastewater treatment plants, hospital water waste, struvite application [38,39], poultry litter [45,59], river water, and sediments [45]. Selective pressure from the environment may be responsible for the prevalence of antibiotic resistance GCs, and the co-selection of antibiotics at these sites along with heavy metals could be other factors facilitating the rise in the development of antibiotic resistance [60].

Different genes were identified in these samples, including aadA1, aadA2, aacA3, and $\operatorname{dfr}$. This result is in line with the conclusions of previously reported studies [45]. The excessive use of biocides for cleaning and washing purposes in hospitals, kitchens, and farms in the form of pesticides could be the main reason for these developments. This concern has been raised by several scientists, who suggested that the use of biocides in general practice, industrial settings, and agricultural farming is a contributing factor to the rise in antibiotic resistance bacterial strains [61]. Organic and inorganic fertilization impact the abundance of AMR and integrons in soil environments and can also introduce resistant bacteria [32-34].

Plant pathogenic bacteria can acquire resistance from soil and environmental bacteria, thereby making these plant bacteria more lethal to plants, as the roots can acquire soil bacteria containing GCs and then facilitate the migration of these GCs from the soil to the roots and, finally, to the phyllosphere. Soil resistant bacteria can enter the plant tissue through stomatal openings or mechanical injuries to the roots and can then be transported within the plant's physiological system and colonize the leaves [33,39]. The differences between the GCs of the studied sites are consistent with those of previous studies. The gene cassette pools here were different from those with other geographical distributions, possibly due to the presence of different anthropogenic and natural inputs [16,22]. On the other hand, the presence of various soil contaminants, soil compositions, and types of microbial biomass may influence the soil microbiome and enhance the dissemination of ARGs [23,24]. Our study showed that the GCs are distinct from those in previously reported studies. Moreover, various sites have a distinct pool of GCs, and these various microbial communities may drive the proliferation and development of GCs in integrons [11]. For bacterial adaptation and evolution, GCs are the most significant components that interact with this specific environment [53,62].

\section{Conclusions}

Bacterial evolution is greatly advanced by integrons and between integrons. Class-I integrons play a core role in the dissemination of different genes across the ecosystem. The present study investigated the role of agriculture in the dissemination of integrons and determined their role in the development of antimicrobial resistance. This study highlights the increased concentration of integrons and the undiscovered pool of GCs. The incidence of antimicrobial GCs in all the investigated samples highlights the role of agriculture in the transmission of antimicrobial resistance. The presence of GCs representing the family glucosyl hydrolase further highlights the dispersal of important pathological genes in the agricultural system. The shared GCs between the effluent and crop soil environments, indicates that these s flow from soil environments to effluent environments, the latter of which often lead to streams and rivers, thereby playing a significant role in the dissemination of integrons and their cassette arrays into water bodies. In return, this process has an impact on both human and non-human populations, including plants. Continuous monitoring of Class-I integrons in different agricultural systems will further contribute to the current knowledge of bacterial evolution and aid in designing relevant reclamation strategies.

Author Contributions: Conceptualization, N.A., R.W. and B.C.; Methodology, N.A. and R.W.; Investigation, N.A., Y.L., D.X., Z.Q. and I.A.; Resources, R.W. and B.C.; Data curation, Y.L., Z.Q., and D.X.; Writing-original draft preparation, N.A.; Writing-review and editing, R.W., A.U.d. and I.A.; Supervision, R.W., B.C., and T.L. All authors have read and agreed to the published version of the manuscript. 
Funding: This study was financially supported by National Key R\&D Program of China (2018YFD0201100) and State Key Laboratory for Conservation and Utilization of Subtropical Agro-bio-resources (SKLCUSA-a201913).

Conflicts of Interest: The authors declare no conflict of interest.

\section{References}

1. Argüello, H.; Guerra, B.; Rodríguez, I.; Rubio, P.; Carvajal, A.J.G. Characterization of antimicrobial resistance determinants and class 1 and class 2 integrons in Salmonella enterica spp., multidrug-resistant isolates from pigs. Genes 2018, 9, 256. [CrossRef] [PubMed]

2. Zhang, S.; Yang, H.; Rehman, M.U.; Yang, K.; Dong, M.; Yang, J.; Wang, M.; Jia, R.; Chen, S.; Liu, M.J.E.; et al. Class 1 integrons as predominant carriers in Escherichia coli isolates from waterfowls in Hainan, China. Ecotoxicol. Environ. Saf. 2019, 183, 109514. [CrossRef] [PubMed]

3. Cambray, G.; Sanchez-Alberola, N.; Campoy, S.; Guerin, É.; da Re, S.; González-Zorn, B.; Ploy, M.C.; Barbé, J.; Mazel, D.; Erill, I.; et al. Prevalence of SOS-mediated control of integron integrase expression as an adaptive trait of chromosomal and mobile integrons. Mobile DNA 2011, 2, 6. [CrossRef] [PubMed]

4. Tansirichaiya, S. Investigation of Mobile Genetic Elements and Antimicrobial Resistance Genes in Human Oral Metagenomic DNA. Ph.D Thesis, UCL University College London, London, UK, 2017.

5. Hall, R.M.; Collis, C.M. Antibiotic resistance in gram-negative bacteria: The role of gene cassettes and integrons. Drug Resist. Updates 1998, 1, 109-119. [CrossRef]

6. Boucher, Y.; Labbate, M.; Koenig, J.E.; Stokes, H.W. Integrons: Mobilizable platforms that promote genetic diversity in bacteria. Trends Microbiol. 2007, 15, 301-309. [CrossRef]

7. Wu, Y.W.; Doak, T.G.; Ye, Y. The gain and loss of chromosomal integron systems in the Treponema species. BMC Evol. Biol. 2013, 13, 16. [CrossRef] [PubMed]

8. Akrami, F.; Rajabnia, M.; Pournajaf, A. Resistance integrons; A mini review. CJIM 2019, 10, 370.

9. Gillings, M.R. Integrons: Past, present, and future. Microbiol. Mol. Biol. Rev. 2014, 78, 257-277. [CrossRef]

10. Ghaly, T.M.; Geoghegan, J.L.; Tetu, S.G.; Gillings, M.R. The peril and promise of integrons: Beyond antibiotic resistance. Trends Microbiol. 2020, 28, 455-464. [CrossRef]

11. Stokes, H.T.; Hall, R.M. A novel family of potentially mobile DNA elements encoding site-specific gene-integration functions: Integrons. Mol. Microbiol. 1989, 3, 1669-1683. [CrossRef]

12. Deng, Y.; Bao, X.; Ji, L.; Chen, L.; Liu, J.; Miao, J.; Chen, D.; Bian, H.; Li, Y.; Yu, G.; et al. Resistance integrons: Class 1, 2 and 3 integrons. Ann. Clin. Microbiol. Antimicrob. 2015, 14, 45. [CrossRef] [PubMed]

13. Partridge, S.R.; Tsafnat, G.; Coiera, E.; Iredell, J.R. Gene cassettes and cassette arrays in mobile resistance integrons. FEMS Microbiol. Rev. 2009, 33, 757-784. [CrossRef] [PubMed]

14. Wu, Y.W.; Rho, M.; Doak, T.G.; Ye, Y. Oral spirochetes implicated in dental diseases are widespread in normal human subjects and carry extremely diverse integron gene cassettes. Appl. Environ. Microbiol. 2012, 78, 5288-5296. [CrossRef] [PubMed]

15. Zhang, A.N.; Li, L.G.; Ma, L.; Gillings, M.R.; Tiedje, J.M.; Zhang, T. Conserved phylogenetic distribution and limited antibiotic resistance of class 1 integrons revealed by assessing the bacterial genome and plasmid collection. Microbiome 2018, 6, 130. [CrossRef] [PubMed]

16. Elsaied, H.; Stokes, H.W.; Kitamura, K.; Kurusu, Y.; Kamagata, Y.; Maruyama, A. Marine integrons containing novel integrase genes, attachment sites, attI, and associated gene cassettes in polluted sediments from Suez and Tokyo Bays. ISME J. 2011, 5, 1162-1177. [CrossRef]

17. Elsaied, H.; Stokes, H.; Nakamura, T.; Kitamura, K.; Fuse, H.; Maruyama, A. Novel and diverse integron integrase genes and integron-like gene cassettes are prevalent in deep-sea hydrothermal vents. Environ. Microbiol. 2007, 9, 2298-2312. [CrossRef]

18. Amann, R.I.; Ludwig, W.; Schleifer, K.H. Phylogenetic identification and in situ detection of individual microbial cells without cultivation. Microbiol. Mol. Biol. Rev. 1995, 59, 143-169. [CrossRef]

19. Stokes, H.W.; Holmes, A.J.; Nield, B.S.; Holley, M.P.; Nevalainen, K.H.; Mabbutt, B.C.; Gillings, M.R. Gene cassette PCR: Sequence-independent recovery of entire genes from environmental DNA. Appl. Environ. Microbiol. 2001, 67, 5240-5246. [CrossRef]

20. Cycoń, M.; Mrozik, A.; Piotrowska-Seget, Z. Antibiotics in the soil environment-Degradation and their impact on microbial activity and diversity. Front. Microbiol. 2019, 10, 338. 
21. Negreanu, Y.; Pasternak, Z.; Jurkevitch, E.; Cytryn, E. Impact of treated wastewater irrigation on antibiotic resistance in agricultural soils. Environ. Sci. Technol. 2012, 46, 4800-4808. [CrossRef]

22. Cerqueira, F.; Christou, A.; Fatta-Kassinos, D.; Vila-Costa, M.; Bayona, J.M.; Piña, B. Effects of prescription antibiotics on soil-and root-associated microbiomes and resistomes in an agricultural context. Front. Microbiol. 2020, 400, 123208.

23. Mahbub, K.R.; King, W.L.; Siboni, N.; Nguyen, V.K.; Rahman, M.M.; Megharaj, M.; Seymour, J.R.; Franks, A.E.; Labbate, M. Long-lasting effect of mercury contamination in the soil microbiome and its co-selection of antibiotic resistance. Environ. Pollut. 2020, 265, 115057. [CrossRef] [PubMed]

24. Fierer, N. Embracing the unknown: Disentangling the complexities of the soil microbiome. Nat. Rev. Microbiol. 2017, 15, 579-590. [CrossRef] [PubMed]

25. Wolters, B.; Kyselková, M.; Krögerrecklenfort, E.; Kreuzig, R.; Smalla, K. Transferable antibiotic resistance

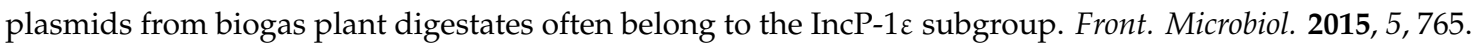
[CrossRef] [PubMed]

26. Han, X.M.; Hu, H.W.; Chen, Q.L.; Yang, L.Y.; Li, H.L.; Zhu, Y.G.; Li, X.Z.; Ma, Y.B. Antibiotic resistance genes and associated bacterial communities in agricultural soils amended with different sources of animal manures. Soil Biol. Biochem. 2018, 126, 91-102. [CrossRef]

27. Jechalke, S.; Heuer, H.; Siemens, J.; Amelung, W.; Smalla, K. Fate and effects of veterinary antibiotics in soil. Trends. Microbiol. 2014, 22, 536-545. [CrossRef]

28. Ding, G.C.; Radl, V.; Schloter-Hai, B.; Jechalke, S.; Heuer, H.; Smalla, K.; Schloter, M. Dynamics of soil bacterial communities in response to repeated application of manure containing sulfadiazine. PLoS ONE 2014, 9, e92958. [CrossRef]

29. Forsberg, K.J.; Patel, S.; Gibson, M.K.; Lauber, C.L.; Knight, R.; Fierer, N.; Dantas, G. Bacterial phylogeny structures soil resistomes across habitats. Nature 2014, 509, 612-616. [CrossRef]

30. Czekalski, N.; Berthold, T.; Caucci, S.; Egli, A.; Bürgmann, H. Increased levels of multiresistant bacteria and resistance genes after wastewater treatment and their dissemination into Lake Geneva, Switzerland. Front. Microbiol. 2012, 3, 106. [CrossRef]

31. Motarjemi, Y.; Moy, G.; Todd, E. Encyclopedia of Food Safety; Academic Press: Cambridge, MA, USA, 2013.

32. Nõlvak, H.; Truu, M.; Kanger, K.; Tampere, M.; Espenberg, M.; Loit, E.; Raave, H.; Truu, J. Inorganic and organic fertilizers impact the abundance and proportion of antibiotic resistance and integron-integrase genes in agricultural grassland soil. Sci. Total. Environ. 2016, 562, 678-689. [CrossRef]

33. Chen, Q.L.; An, X.L.; Zhu, Y.G.; Su, J.Q.; Gillings, M.R.; Ye, Z.L.; Cui, L. Application of struvite alters the antibiotic resistome in soil, rhizosphere, and phyllosphere. Environ. Sci. Technol. 2017, 51, 8149-8157. [CrossRef] [PubMed]

34. Jechalke, S.; Schreiter, S.; Wolters, B.; Dealtry, S.; Heuer, H.; Smalla, K. Widespread dissemination of class 1 integron components in soils and related ecosystems as revealed by cultivation-independent analysis. Front. Microbiol. 2014, 4. [CrossRef] [PubMed]

35. Ali, I.; He, L.; Ullah, S.; Quan, Z.; Wei, S.; Iqbal, A.; Munsif, F.; Shah, T.; Xuan, Y.; Luo, Y. Biochar addition coupled with nitrogen fertilization impacts on soil quality, crop productivity, and nitrogen uptake under double-cropping system. Food Energy Secur. 2020, 9, e208. [CrossRef]

36. Rosser, S.J.; Young, H.K. Identification and characterization of class 1 integrons in bacteria from an aquatic environment. J. Antimicrob. Chemother. 1999, 44, 11-18. [CrossRef]

37. Gaze, W.H.; Zhang, L.; Abdouslam, N.A.; Hawkey, P.M.; Calvo-Bado, L.; Royle, J.; Brown, H.; Davis, S.; Kay, P.; Boxall, A.B.; et al. Impacts of anthropogenic activity on the ecology of class 1 integrons and integron-associated genes in the environment. ISME J. 2011, 5, 1253-1261.

38. Stalder, T.; Barraud, O.; Jové, T.; Casellas, M.; Gaschet, M.; Dagot, C.; Ploy, M.C. Quantitative and qualitative impact of hospital effluent on dissemination of the integron pool. ISME J. 2014, 8, 768-777.

39. An, X.L.; Chen, Q.L.; Zhu, D.; Su, J.Q. Distinct effects of struvite and biochar amendment on the class 1 integron antibiotic resistance gene cassettes in phyllosphere and rhizosphere. Sci. Total. Environ. 2018, 631, 668-676. [CrossRef]

40. Kristiansson, E.; Fick, J.; Janzon, A.; Grabic, R.; Rutgersson, C.; Weijdegård, B.; Söderström, H.; Larsson, D.J. Pyrosequencing of antibiotic-contaminated river sediments reveals high levels of resistance and gene transfer elements. PLoS ONE 2011, 6, e17038. [CrossRef] 
41. Barraud, O.; Casellas, M.; Dagot, C.; Ploy, M.C. An antibiotic-resistant class 3 integron in an Enterobacter cloacae isolate from hospital effluent. CMI 2013, 19, E306-E308. [CrossRef]

42. Chen, Q.; An, X.; Li, H.; Su, J.; Ma, Y.; Zhu, Y.G. Long-term field application of sewage sludge increases the abundance of antibiotic resistance genes in soil. Environ. Int. 2016, 92, 1-10. [CrossRef]

43. Bastian, M.; Heymann, S.; Jacomy, M. Gephi: An open source software for exploring and manipulating networks. In Proceedings of the Third international AAAI Conference on Weblogs and Social Media, The Pennsylvania State University, Philadelphia, PA, USA, 17 May 2009.

44. Zhang, X.X.; Zhang, T.; Zhang, M.; Fang, H.H.; Cheng, S.P. Characterization and quantification of class 1 integrons and associated gene cassettes in sewage treatment plants. Appl. Microbiol. Biotechnol. 2009, 82, 1169-1177. [CrossRef] [PubMed]

45. Amos, G.C.; Ploumakis, S.; Zhang, L.; Hawkey, P.M.; Gaze, W.H.; Wellington, E.M. The widespread dissemination of integrons throughout bacterial communities in a riverine system. ISME J. 2018, 12, 681-691. [CrossRef] [PubMed]

46. Kang, H.Y.; Jeong, Y.S.; Oh, J.Y.; Tae, S.H.; Choi, C.H.; Moon, D.C.; Lee, W.K.; Lee, Y.C.; Seol, S.Y.; Cho, D.T.; et al. Characterization of antimicrobial resistance and class 1 integrons found in Escherichia coli isolates from humans and animals in Korea. J. Antimicrob. Chemother. 2005, 55, 639-644. [CrossRef] [PubMed]

47. Cocchi, S.; Grasselli, E.; Gutacker, M.; Benagli, C.; Convert, M.; Piffaretti, J.C. Distribution and characterization of integrons in Escherichia coli strains of animal and human origin. FEMS Immunol. Med. Microbiol. 2007, 50, 126-132. [CrossRef]

48. Wright, M.S.; Baker-Austin, C.; Lindell, A.H.; Stepanauskas, R.; Stokes, H.W.; McArthur, J.V. Influence of industrial contamination on mobile genetic elements: Class 1 integron abundance and gene cassette structure in aquatic bacterial communities. ISME J. 2008, 2, 417-428. [CrossRef]

49. Rosewarne, C.P.; Pettigrove, V.; Stokes, H.W.; Parsons, Y.M. Class 1 integrons in benthic bacterial communities: Abundance, association with Tn 402-like transposition modules and evidence for coselection with heavy-metal resistance. FEMS Microbiol. Ecol. 2010, 72, 35-46. [CrossRef]

50. Gou, M.; Hu, H.W.; Zhang, Y.J.; Wang, J.T.; Hayden, H.; Tang, Y.Q.; He, J.Z. Aerobic composting reduces antibiotic resistance genes in cattle manure and the resistome dissemination in agricultural soils. Sci. Total Environ. 2018, 612, 1300-1310. [CrossRef]

51. Schröder, G.; Schuelein, R.; Quebatte, M.; Dehio, C. Conjugative DNA transfer into human cells by the VirB/VirD4 type IV secretion system of the bacterial pathogen Bartonella henselae. PNAS 2011, 108, 14643-14648. [CrossRef]

52. Wallden, K.; Rivera-Calzada, A.; Waksman, G. Microreview: Type IV secretion systems: Versatility and diversity in function. Cell. Microbiol. 2010, 12, 1203-1212. [CrossRef]

53. Koenig, J.E.; Bourne, D.G.; Curtis, B.; Dlutek, M.; Stokes, H.; Doolittle, W.F.; Boucher, Y. Coral-mucus-associated vibrio integrons in the great barrier reef: Genomic hotspots for environmental adaptation. ISME J. 2011, 5, 962-972. [CrossRef]

54. Gatica, J.; Tripathi, V.; Green, S.; Manaia, C.M.; Berendonk, T.; Cacace, D.; Merlin, C.; Kreuzinger, N.; Schwartz, T.; Fatta-Kassinos, D.; et al. High throughput analysis of integron gene cassettes in wastewater environments. Environ. Sci. Technol. 2016, 50, 11825-11836. [CrossRef] [PubMed]

55. Ma, L.; Li, A.D.; Yin, X.L.; Zhang, T. The prevalence of integrons as the carrier of antibiotic resistance genes in natural and man-made environments. Environ. Sci. Technol. 2017, 51, 5721-5728. [CrossRef] [PubMed]

56. Reynolds, M.M.; Bogomolnaya, L.; Guo, J.; Aldrich, L.; Bokhari, D.; Santiviago, C.A.; McClelland, M.; Andrews-Polymenis, H. Abrogation of the twin arginine transport system in Salmonella enterica serovar Typhimurium leads to colonization defects during infection. PLoS ONE 2011, 6, e15800. [CrossRef] [PubMed]

57. Intra, J.; Pavesi, G.; Horner, D.S. Phylogenetic analyses suggest multiple changes of substrate specificity within the glycosyl hydrolase 20 family. BMC Evol. Bio. 2008, 8, 214. [CrossRef]

58. Boer, J.L.; Mulrooney, S.B.; Hausinger, R.P. Nickel-dependent metalloenzymes. Arch. Biochem. Biophys. 2014, 544, 142-152. [CrossRef]

59. Nandi, S.; Maurer, J.J.; Hofacre, C.; Summers, A.O. Gram-positive bacteria are a major reservoir of Class 1 antibiotic resistance integrons in poultry litter. Proc. Natl. Acad. Sci. USA 2004, 101, 7118-7122. [CrossRef]

60. Lázár, V.; Nagy, I.; Spohn, R.; Csörgő, B.; Györkei, Á.; Nyerges, Á.; Horváth, B.; Vörös, A.; Busa-Fekete, R.; Hrtyan, M.; et al. Genome-wide analysis captures the determinants of the antibiotic cross-resistance interaction network. Nat. Commun. 2014, 5, 4352. [CrossRef] 
61. Manyi-Loh, C.; Mamphweli, S.; Meyer, E.; Okoh, A. Antibiotic use in agriculture and its consequential resistance in environmental sources: Potential public health implications. Molecules 2018, 23, 795. [CrossRef]

62. Thanner, S.; Drissner, D.; Walsh, F. Antimicrobial resistance in agriculture. MBio 2016, 7, e02227-15. [CrossRef]

(C) 2020 by the authors. Licensee MDPI, Basel, Switzerland. This article is an open access article distributed under the terms and conditions of the Creative Commons Attribution (CC BY) license (http://creativecommons.org/licenses/by/4.0/). 